\title{
State-of-the-art of transcatheter treatment of aortic valve stenosis and the overview of the InFlow project aiming at developing the first Polish TAVI system
}

\author{
Mateusz Kachel ${ }^{1}$, Krzysztof Milewski ${ }^{1,2}$, Piotr Buszman ${ }^{1,3}$, Magdalena Michalak ${ }^{1}$, \\ Wojciech Domaradzki ${ }^{1}$, Witold Gerber ${ }^{1}$, Joanna Śliwka ${ }^{3,4}$, Jerzy Nożyński ${ }^{3,4}$, \\ Michał Sobota ${ }^{3}$, Piotr Hirnle ${ }^{1,2}$, Marzena Białek-Brodocz ${ }^{6}$, Michał Zembala ${ }^{3,4}$, \\ Mariusz Pawlak ${ }^{7}$, Emil Płowiecki ${ }^{8}$, Janusz Kasperczyk ${ }^{5}$, Arkadiusz Mężyk ${ }^{7}$, \\ Andrzej Bochenek ${ }^{1}$, Paweł Buszman ${ }^{1,4}$
}

${ }^{1}$ Center for Cardiovascular Research and Development of American Heart of Poland, Katowice, Poland

${ }^{2}$ Innovations for Heart and Vessels Ltd.

${ }^{3}$ Silesian Center for Heart Diseases, Zabrze, Poland

${ }^{4}$ Medical University of Silesia, Katowice, Poland

${ }^{5}$ Polish Academy of Sciences, Centre of Polymer and Carbon Materials, Zabrze, Poland

${ }^{6}$ Experimental Station of National Research Institute of Animal Production

named Prof. M. Czaja, Grodziec Slaski, Poland

${ }^{7}$ Silesian University of Technology, Gliwice, Poland

${ }^{8}$ Balton Ltd.

\begin{abstract}
Initial experience of transcatheter aortic valve implantation (TAVI) or replacement (TAVR) has appeared as a promising minimally invasive technology for patients disqualified from surgical treatment (SAVR). Safety and efficacy of TAVI has been analyzed and assessed through numerous registries and trials. Furthermore, results obtained from comparative TAVI vs. SAVR trials proved that both treatments can be considered equal in terms of post-procedural mortality and morbidity in high-risk, as well as lower risk patients. However, there are still some issues that have to be addressed, such as higher chance of paravalvular leakage, vascular injuries, conduction disturbances, malpositioning and the yet unmet problem of insufficient biological valves durability. Recent technological developments along with the learning curve of operators prove a great potential for improvement of TAVI and a chance of surpassing SAVR in various groups of patients in the near future. In pursuit of finding new solutions, the CardValve Consortium consisting of leading scientific and research institutions in Poland has been created. Under the name of InFlow and financial support from the National Center for Research and Development, they have started a project with the aim to design, create and implement into clinical practice the first, Polish, low-profile TAVI valve system, utilizing not only biological but also artificial, polymeric-based prosthesis. This review focuses on current developments in TAVI technologies including the InFlow project. (Cardiol J 2017; 24, 6: 685-694)
\end{abstract}

Key words: aortic stenosis, TAVI, prosthetic valves, InFlow

Address for correspondence: Paweł Buszman, MD, PhD, Center for Cardiovascular Research and Development of American Heart of Poland, ul. 41 Czajek, 40-761 Katowice, Poland, tel: +48 32 758-65-00, fax: +48 3225102 11, e-mail: pawel.buszman@ahop.pl

Received: 01.11.2017 Accepted: 08.11.2017 


\section{Aortic stenosis:} The scope of the problem

Valvular heart defects pose a serious challenge for healthcare systems in developed countries around the world, with aortic stenosis (AS) presenting the highest frequency of occurrence among them. Along with aging of societies, the prevalence of this disease rises drastically from $0.7 \%$ in patients $18-44$ years old to $13.3 \%$ in patients $\geq 75$ years old [1].The European Society of Cardiology (ESC) in their recommendations for 2012 estimates, that around $2-7 \%$ of people over 65 years in Europe and the United States suffers from AS [2]. The main cause for its development remains valve calcification that increases with age. Calcium particles deposit in the valve, especially in the leaflets, leading to their thickening and hardening. As a result, proper function of the valve is impaired. This mechanism differs from that occurring in younger patients, in whom congenital defects are the most common cause of valve failure. Thanks to the development of medicine and rise of health awareness among men, rheumatic etiology, which was regarded as the main cause of valvular disease in the past, became a rare inducing factor. The disease itself can be divided into two phases: asymptomatic and symptomatic. Outcome prediction in the asymptomatic phase is usually good and implementing medical treatment is sufficient. Duration of this period is long (several years), but varies among individuals. The onset of symptoms marks the beginning of the second, symptomatic phase, characterized by a rapid progression of illness.

The 5-year mortality, a parameter used to describe the severity of the disease is exceptionally low for the symptomatic phase of AS, reaching a survival rate of about $15-50 \%$ in groups of untreated patients [2]. This indicates a need for thorough diagnostics in risk group patients, conscientious monitoring and quick implementation of proper therapy. Searching for specific factors, which were identified as having a predictive value for turning AS into symptomatic phase is crucial. This includes: clinical factors such as older age or diffuse atherosclerosis, presence of calcification in components of aortic valve apparatus, low ejection fraction, hypertension, renal failure, positive results of exercise test meaning a high probability of symptoms onset within the next 12 months and elevated biomarkers (natriuretic peptide) [3].

\section{Aortic valve replacement}

Currently the gold standard in treatment of AS is surgical replacement of the valve (aortic valve replacement [AVR]), which comprises removal of a degenerated one and implantation of a biological or mechanical prosthesis in its place. In patients under 70 years, without serious comorbidities, perioperational mortality is $1-3 \%$, however in older patients it rises to 4-8\% [2]. Additional factors like concomitant diseases, female sex, patient fragility, higher New York Heart Association (NYHA) class or left ventricle dysfunction exacerbate the situation, drastically increasing the risk of death.

The development of medicine, improvement of civilizational life conditions and rise of social consciousness has resulted in increases of average lifespan. Mean age has risen, which directly translates into growth of perioperational risk and increasing difficulty in treatment of these patients. Studies show that $1 / 3$ of patients over 75 years cannot be qualified for surgical treatment [4]. This is mainly due to the very high risk of perioperative mortality. A need for new, less invasive treatment, customized for such patients has emerged.

\section{Transcatheter aortic valve replacement - TAVI}

In 1989, Henning-Rud Andersen first implanted an original model of a balloon-expandable catheter-mounted stented valve within the aorta of pigs, using a handmade mesh containing a porcine valve [5]. Over a decade later in 2002 the first successful implantation of transcatheter aortic valve in clinical settings was performed by Alain Cribier in a patient suffering from severe AS caused by calcification [6]. The method, under the name of TAVI (transcatheter aortic valve implantation) or TAVR (transcatheter aortic valve replacement), has been quickly implemented in clinical practice, marking the beginning of a new era of AS treatment. Depending on the option, biological prosthesis of the valve is implanted using dedicated catheter, with no need for surgery, via transapical (through the apex of the heart), or transvascular (mainly using femoral artery) route. Data from European Sentinel Registry of Transcatheter Aortic Valve Implantation indicate that femoral access is not only the preferred one, but also the safest (mortality of $5.9 \%$ in comparison to $12.8 \%$ in transapical and $9.7 \%$ in other access routes) [7]. Introducing this 
technique happened to be a milestone and a chance for patients with critical health conditions who would have had unfavorable outcomes of surgery. Results of PARTNER 1B trial prove this statement. Performed comparison between TAVI and medical management in elderly patients deemed inoperable showed almost $22 \%$ difference in 5 year mortality (71.8\% in the TAVI group vs. $93.6 \%$ in the standard treatment group; HR 0.50; 95\% CI 0.39-0.65; p < $<0.0001$ ) and $26 \%$ difference in number of patients presenting with satisfying results in heart failure management (NYHA class 1 and 2 symptoms) after 5 years subsequent to the procedure $(86 \%$ of TAVI group vs. $60 \%$ of the standard treatment group) [8].

Safety and efficacy of TAVI has been analyzed and assessed through numerous registries and trials conducted. However, TAVI vs. surgical aortic valve replacement (SAVR) comparison has been evaluated in only 5 randomized trials, of which 4 were completed. The STACCATO trial was terminated early by the data safety monitoring board. The remaining (Table 1) include two high-risk trials (PARTNER 1A, US CoreValve High Risk) and three that covered non-high-risk patient populations (NOTION, PARTNER 2A, SURTAVI) [9, 10].

PARTNER 1A is the longest running trial with 5 year follow up, CoreValve was already in progress for 3 years and the other two for 2 years each. The most relevant outcomes for TAVI vs. SAVR are as follows.

PARTNER 1A 5 years - no difference in mortality ( $67.8 \%$ vs. $62.4 \%$; $=0.76)$, however TAVI patients more often suffered from major vascular complications ( $11.9 \%$ vs. $4.7 \% ; \mathrm{p}=0.0002)$ and SAVR patients from major bleeding $(26.6 \%$ vs. $34.4 \%$; $=0.003$ ) [11].

US CoreValve High Risk 3 years - no difference in mortality, but trending towards statistical significance in favor of TAVI $(32.9 \%$ vs. $39.1 \%$; $\mathrm{p}=0.068$ ). TAVI patients were more prone to the occurrence of major vascular complications and need for permanent pacemaker implant $(7.1 \%$ vs. $2.0 \% ; \mathrm{p}=0.001 ; 28.0 \%$ vs. $14.5 \% ; \mathrm{p}<0.001)$, whereas SAVR patients were prone to the risk of major bleeding and developing acute kidney injury (AKI) $(32.8 \%$ vs. $40.0 \% ; p=0.045 ; 6.2 \%$ vs. $15.1 \%$; $\mathrm{p}<0.001)$ [12].

NOTION 4 years - no difference in mortality $(20.0 \%$ vs. $23.0 \%$; $p=0.56)$, greater need for permanent pacemaker implantation (PPI) in TAVI group ( $43.7 \%$ vs. $9.0 \%$; p < 0.001), but SAVR patients were at higher risk of developing new atrial fibrillation (AF) or worsening the already existing condition $(24.5 \%$ vs. $60.2 \%$; $<0.001)[13,14]$.
PARTNER 2A 2 years - no difference in mortality $(16.7 \%$ vs. $18.0 \%$; $\mathrm{p}=0.45)$, TAVI patients more often suffered from major vascular complications ( $8.6 \%$ vs. $5.5 \% ; \mathrm{p}=0.006$ ), although SAVR patients were more prone to experience life threatening bleeding complications and develop AKI or new AF (17.3\% vs. $47.0 \%$; $\mathrm{p}<0.001 ; 3.8 \%$ vs. $6.2 \% ; \mathrm{p}=0.02 ; 11.3 \%$ vs. $27.3 \%$; $<0.001)$ [15].

SURTAVI 2 years - no difference in mortality $(11.4 \%$ vs. $11.6 \%)$ and disabling stroke $(2.6 \%$ vs. $4.5 \%$ ) after 24 months, TAVI patients needed PPI more frequently ( $25.9 \%$ vs. $6.6 \%)$ and were at greater risk of presenting with vascular complications ( $6.0 \%$ vs. $1.1 \%)$, however SAVR patients more often suffered from AKI stage 2 or 3 (1.7\% vs. 4.4\%) and developed new $\mathrm{AF}$ (12.9\% vs. $43.4 \%)$ [16].

The results obtained show that TAVI and SAVR are equivalent treatment methods in both high-risk and no-high-risk groups. Frequency of incidence of vascular complications and need for pacemaker implantation after TAVI can be partially explained with the use of older generation valves in the above mentioned studies (Edwards SAPIEN, Medtronic CoreValve and SAPIEN XT) in comparison to the new ones available and many more under evaluation, which address these issues. Technological development along with the learning curve of operators proves a great potential for improvement of TAVI and a chance of surpassing SAVR in various groups of patients in the near future. Optimistic clinical trial results and launching many new studies are reflected by the constantly growing number of TAVRs performed all over the world. A 33-fold increase has been recorded in the number of procedures performed annually in Europe between 2007 and 2011 [17].

\section{TAVI limitations}

Despite undisputed benefits, TAVI, as any other method, is not free from flaws. The most significant flaws are the higher frequency of paravalvular leakage (PVL) in comparison to surgery and the large size of crimped valves requiring sheath of $\geq 14 \mathrm{~F}$, resulting in the risk of vascular injuries during the delivery process. Also the need for pacemaker implantation due to relatively common occurrence of arrhythmias after the procedure and an inability to retrieve most of currently available valves in case of malposition remain important drawbacks. The conduction disorders are said to be connected with protrusion of the prosthesis into the left ventricular outflow tract (LVOT), 


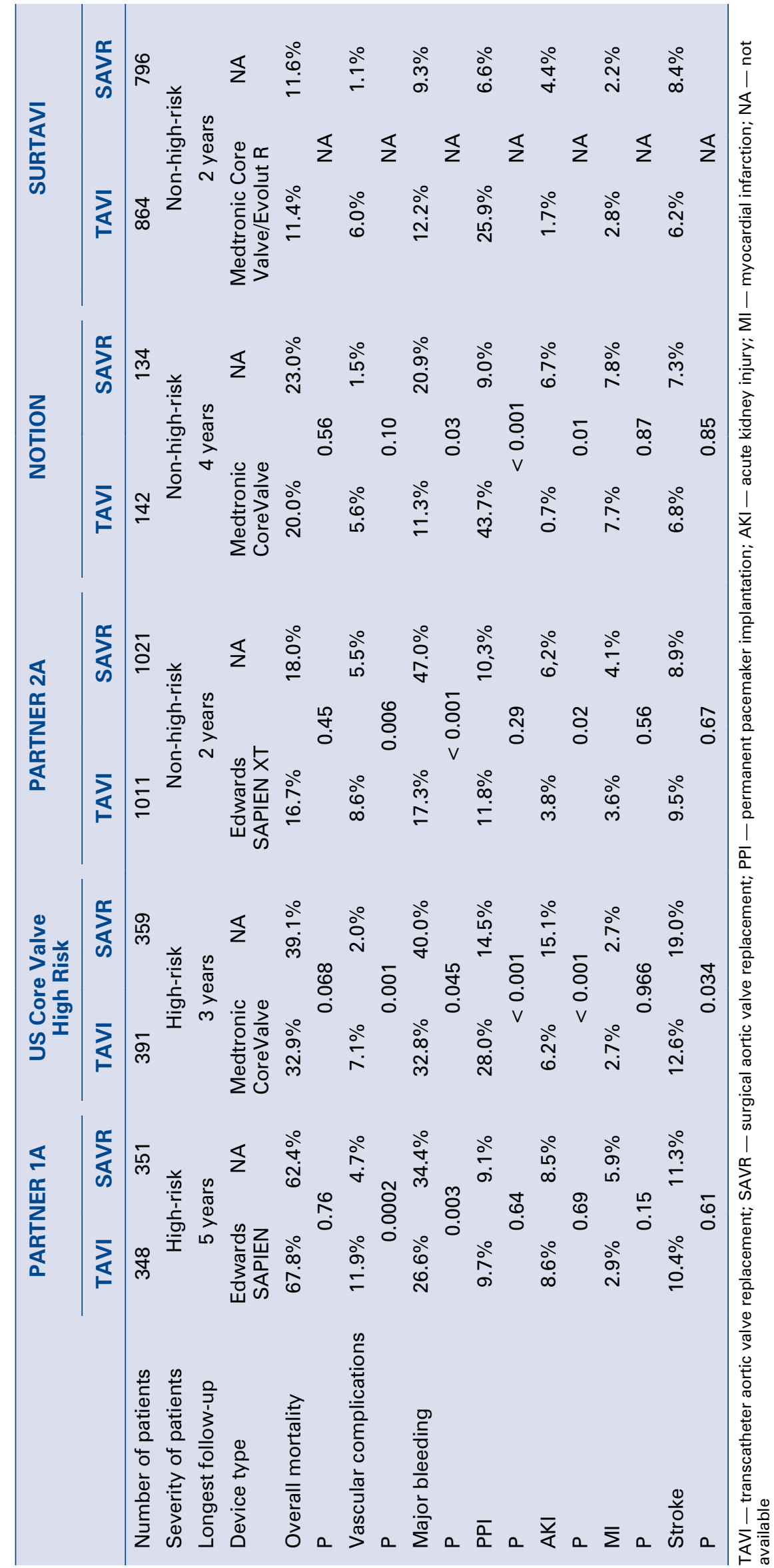


mechanical injuries during predilatation or with the trauma caused by catheters and guidewires [18, 19]. Inaccurate positioning is a rare but serious complication, which may end up with the need for second valve implantation and influences PVL due to impairing conformity of the prosthesis to native annulus. Worth mentioning here are incidences of cerebrovascular events due to ischemia. They can be explained with embolic debris being liberated from the native valve (especially heavy calcified) during the procedure, which then flows to cerebral circulation. Another possible explanation is brain hypoperfusion during valve implantation [20]. To reduce risk, few cerebral embolic protection devices have been developed which either work as a collector or deflector of debris, namely the Claret CE Pro (Claret Medical Inc., Santa Rosa, CA), the Triguard (Keystone Heart, Caesarea, Israel), and the Embrella (Edwards Lifesciences Inc., Irvine, CA) [21].

Bulky delivery systems are the main cause of vascular injuries. Early reports stated that major vascular complications and bleeding occurred in $8-17 \%$ of TAVI patients. Thankfully, due to technological advancement, better patient selection and gains in experience by medical staff, this has decreased to $4-13 \%$ of cases [22]. However, the need for a new low-profile device with a target of at least $12 \mathrm{~F}(3.96 \mathrm{~mm})$ remains, as the number are still high. Developing and introducing a new product, will not only mean greater safety and utility of TAVI, but may also positively affect patient comfort and owing to being less invasive, reduce recovery time. A different approach is creating and including expandable vascular sheaths which provide a temporary passage for prosthesis to prevent injuries. The examples are E-sheath and Solopath, which are also hydrophilic coated. To prevent bleeding associated with the puncture site, several closing devices have been developed to provide better sealing, including: Prostar (Abbott Vascular Inc, Santa Clara, CA), ProGlide (Abbott Vascular, Redwood City, CA), ProMed (ProMed, Santa Clara, CA), InSeal (InSeal Medical, Caesarea, Israel), VivaSure (VivaSure Medical Ltd., Galway, Ireland) [21].

Durability of TAVI prostheses remains in question. Sufficient data exists only for a period of up to 5 years, showing promising results. However, much longer follow up is required for thorough analysis. Given the similarities to surgically implanted bioprostheses, the well known problem of structural valve deterioration can also be an issue in TAVI, especially taking into account trending towards intermediate, younger patients [23]. Seeking new methods of bio material preservation and alternatives in the form of biocompatible polymers should be of the essence.

Another essential case is the cost of implantation and production of the valve, leading to the situation that even highly developed and wealthy countries such as Germany or Switzerland are being able to cover respectively only $36.2 \%$ and $34.5 \%$ of their need with the European mean value holding at $17.9 \%$ [17]. It looks even worse in less wealthy countries like Poland, where healthcare funding is much lower, preventing its broader use and development.

Along with popularizing the method and implementing new technologies the frequency of adverse events and costs of procedure should diminish. Constant education of physicians and other staff will have a positive effect on the safety and ease of implantation, translating into greater comfort for patients. Above mentioned issues pose a great challenge for researchers willing to improve the method.

\section{New designs and solutions}

In recent years new and interesting TAVI devices have been implemented into clinical practice with many more being currently under the evaluation process (Table 2) [24-28]. The coming years will show if they become breakthroughs in transcatheter treatment of aortic valves. Nevertheless, these technologies and solutions will have a chance to further improve the safety and efficacy of TAVI procedures.

Boston Scientific has voluntarily recalled their Lotus valves in February 2017, including the Lotus with depth guard, following reports of problems with the device's locking mechanism. The company expects that the issue will be resolved and device should return to European and other markets in the fourth quarter of 2017 [29].

\section{Edwards SAPIEN 3}

New, commercially available balloon-expandable valve. Bovine pericardial tissue leaflets are mounted on a cobalt chromium alloy frame, which due to enhanced geometry design makes for a low-profile valve of $14 \mathrm{~F}$ enabling the reduction of vascular complications. SAPIEN 3 has an improved delivery system resulting in greater accuracy and lower risk of malpositioning. It also is comprised of an outer skirt of polyethylene terephthalate to minimize PVL [28]. 
Table 2. Currently available and new transcatheter aortic valve implantation valves.

\begin{tabular}{|c|c|c|c|}
\hline Valve & Sheath size & Special features & Status \\
\hline SAPIEN 3 & $14 \mathrm{~F}$ & PET skirt, improved delivery system & CE mark/FDA approved \\
\hline CoreValveEvolut-R & $14 \mathrm{~F}$ equivalent & Repositionable up to $80 \%$ & CE mark/FDA approved \\
\hline CoreValveEvolut PRO & $14 \mathrm{~F}$ equivalent & $\begin{array}{l}\text { Repositionable up to } 80 \% \text {, advanced } \\
\text { sealing with porcine pericardial wrap }\end{array}$ & CE mark/FDA approved \\
\hline Lotus/Lotus Edge* & $18 \mathrm{~F} / 14 \mathrm{~F}$ & $\begin{array}{c}\text { Fully retrievable, mechanical } \\
\text { expansion system, adaptive Seal }{ }^{\mathrm{TM}}, \\
\text { Depth Guard }{ }^{\mathrm{TM}}(\text { Edge })\end{array}$ & CE mark \\
\hline $\begin{array}{l}\text { JenaValve Pericardial } \\
\text { TAVR System }\end{array}$ & Not available & $\begin{array}{l}\text { Clipping mechanism, repositionable } \\
\text { before full deployment }\end{array}$ & Investigational use only \\
\hline Portico & $18 \mathrm{~F}$ & $\begin{array}{l}\text { Linx }^{\mathrm{TM}} \text { anti-calcification technology, } \\
\text { minimal protrusion system, } \\
\text { repositionable before full deployment }\end{array}$ & CE mark \\
\hline Direct Flow Medical & $18 \mathrm{~F}$ & $\begin{array}{l}\text { Inflatable ring cuff frame, fully } \\
\text { retrievable }\end{array}$ & CE mark (production ceased) \\
\hline Edwards CENTERA & $14 \mathrm{~F}$ & $\begin{array}{l}\text { Motorized delivery system, } \\
\text { repositionable before full deployment }\end{array}$ & Investigational use only \\
\hline Acurate neo/TF & $18 \mathrm{~F}$ & $\begin{array}{l}\text { Two-step, single-operator } \\
\text { deployment process, three stabilization } \\
\text { arches, covered with porcine } \\
\text { pericardial skin }\end{array}$ & CE mark only \\
\hline Engager & $32 \mathrm{~F}$ (transapical) & Polyester skirt, control arms & CE mark only (recalled) \\
\hline
\end{tabular}

*Boston Scientific has voluntarily recalled their Lotus valves in February 2017, including the Lotus with depth guard, following reports of problems with the device's locking mechanism. The company expects that the issue will be resolved and device should return to European and other markets in the fourth quarter of 2017 [29]. CE - Conformité Européenne; FDA — Food and Drug Association; PET — polyethylene terephthalate

\section{Medtronic CoreValveEvolut-R}

This self-expanding valve consists of a nitinol frame providing consistent radial force for better sealing. The valve is meant to be recapture- and reposition-able up to around $80 \%$ of deployment. The delivery system is $14 \mathrm{~F}$ equivalent to reduce the incidence of major vascular complications. The 1-year data presented by Ganesh Manoharan at Trancatheter Cardiovascular Therapeutics (TCT) in 2015, showed a moderate PVL rate of $4.3 \%$ and PPI rate of $15.2 \%$. The overall survivability rate was $93.3 \%$ [30].

\section{Medtronic CoreValveEvolut PRO}

Based on the same platform as Evolut-R, $\mathrm{PRO}$ is the new iteration of the CoreValve family. It contains an advanced sealing technology with porcine pericardial wrap on the lower part of the prosthesis, helping to reduce the number of incidences of PVL. The valve is delivered with $14 \mathrm{~F}$ equivalent delivery system. 30 -day result data presented at American College of Cardiology (ACC) 2017 showed good hemodynamics and the need for a pacemaker being as low as $10 \%$ [31]. Evolut PRO was approved by the Food and Drug Association (FDA) early this year and recently received Conformité Européenne (CE) mark [32].

\section{Boston Scientific Lotus/Lotus Edge valve}

The Lotus system consists of bovine pericardial tissue leaflets mounted on a nitinol frame. The valve is pre-attached to the delivery system. A mechanical expansion system enables full retrieval and repositioning of the valve unless it has been released. The operator can deploy the valve, leaving it in a lock position to evaluate positioning and perform necessary changes. Additionally, part of the frame is surrounded by Adaptive Seal ${ }^{\mathrm{TM}}$ to minimize PVL. The valve is currently available in CE mark countries and is under evaluation to obtain FDA approval $[33,34]$. Lotus Edge is the next iteration of Lotus valve, characterized by a reduced profile of delivery catheter, which is also more flexible, enabling easier maneuvering and better control. Another important aspect is the introduction of a Depth Guard ${ }^{\mathrm{TM}}$ system to minimize the protrusion of the valve into LVOT, thus diminishing the risk of post-procedural conduction disturbances and the need for PPI. First results from a feasibility trial presented at the TCT 2016 seems promising. Lotus Edge is available in CE mark countries [35]. 


\section{JenaValve Pericardial TAVR System}

The self-expanding, nitinol frame system is based on a company's previous CE marked JenaValve porcine root system. It is designed to address both the stenosis and regurgitation issue. The valve uses a unique clipping mechanism, enabling fixation to native leaflets for greater stability. The efficiency of this mechanism is said to be independent of the level of calcification of a native valve. Producer declares that the valve is to be repositionable even after locator release, but prior to stent deployment, lowering the risk of malpositioning. Currently, the system is enabled exclusively for investigational use [36].

\section{St. Jude Medical Portico valve}

Portico is a bovine leaflets valve, processed with Linx ${ }^{\mathrm{TM}}$ anti-calcification technology, based on nitinol stent frame with a cuff, also made of bovine pericardial tissue, working as a sealing zone to minimize PVL [37]. The valve is gradually deployed using $18 \mathrm{~F}$ delivery system, allowing recapturing and repositioning of the valve until the complete deployment. The height of the valve is designed to result in minimal protrusion into the LVOT, reducing the incidence of post-procedural pacemaker implantation. Currently Portico bears a CE mark, available in Europe and is continuing its IDE trial in the United States [38].

\section{Direct flow valve}

The Direct Flow Medical aortic valve (Direct Flow Medical, Santa Rosa, CA, USA) is a nonmetallic percutaneous valve with an inflatable ring cuff frame designed to encircle and capture the native valve annulus, thereby ensuring anchoring of the bioprosthesis and minimizing potential paravalvular aortic regurgitation, dislodgment or migration [39]. The valve is designed to conform to individual anatomy for a better seal and is meant to be fully retrievable and repositionable prior to deployment. The inflatable rings are pressurized with saline and contrast solution resulting in great visibility of the prosthesis, translating into easier and more accurate positioning with no need for contrast injections during deployment. After evaluation the solution is then exchanged for a polymer, which solidifies making for a permanent support structure [40]. The system has received CE mark, however it is not available presently. The company closed and had ceased production at the end of November 2016 after failing to secure financing [41].

\section{Other valves}

Other valves worth mentioning are: Edwards CENTERA valve, characterized with low profile of $14 \mathrm{~F}$ and is self-expanding, retrievable and repositionable until full deployment. The use of a motorized delivery system allows for single operator use [22]. So far the valve is enabled for investigational use only. Thirty-day outcomes presented at EuroPCR 2017 showed excellent results in terms of mortality (1\%) and need for pacemaker implantation (4.9\%) [42]. Symetis Acurate neo/TF system facilitates an easy two-step, single-operator deployment process. The device is comprised of three stabilization arches for axial alignment, an upper-crown for capping the aortic annulus, and a lower-crown that is opened over the native valve for full deployment. Additionally, the stent is covered with porcine pericardial skin to minimize leakage. The system has received CE mark and is available on the European market [43, 44]. Medtronic Engager is a self-expanding valve with nitinol stent frame covered with polyester skirt. The system presents with control arms for tactile feedback during deployment, enabling more precise positioning and greater conformity to the native annulus, resulting in a reduction of PVL $[45,46]$. The Medtronic Engager system is CE mark approved. Despite positive early results, Medtronic decided to voluntarily recall all devices in 2015 after reviewing 2-year data from Engager European Pivotal trial showing suboptimal results of mean gradient [47].

\section{InFlow project}

Bearing in mind the above mentioned TAVI limitations, as well as specificity of the Polish medical market, CardValve Consortium has been brought to life and commenced work on an InFlow project. Its purpose is to create the first Polish, low profile valve for transcatheter implantation. Through funds received from the National Centre for Research and Development as a part of STRATEGMED program, this vision has become possible to accomplish.

The aim of the Consortium is to introduce to the market a valve, which owing to the low profile, will enable minimization of vascular injuries connected with the delivery process and due to being composed of new materials will be characterized by higher biocompatibility and durability of single elements which are safer for patients. The desired 
size of the whole system is $12 \mathrm{~F}$ or less, which would be a huge step forward. The newest, state of the art valves like Medtronic Evolut- $\mathrm{R}^{\mathrm{TM}}$ or Edwards SAPIEN 3 have a sheath size of $14 \mathrm{~F}$ and are the smallest among competitors. Others normally start from $18 \mathrm{~F}$. Implementing a native product in clinical practice will also reduce costs of procedures using TAVI valves, considering its lower price in comparison to currently available products. It is hoped to result in greater accessibility for patients.

\section{Project timeline}

Project began on $1^{\text {st }}$ of October 2014 and is planned to conclude in the second half of 2017. The protocol assumes selection of the most optimal valve design and materials for prototype production, and subsequently implementation of preclinical studies in order to introduce this device into clinical tests. The aim of the project is not only creating a new valve itself, but also a complete implantation device consisting of a delivery system made of dedicated inflating balloon, self-positioning frame and vascular sheath.

Obtaining proper material for leaflet production is essential. For this purpose, various polymer combinations are being tested under laboratory conditions to assess their mechanical properties and hemocompatibility as well as their biocompatibility on animal models. Simultaneously, research on finding biological material is being carried out, focused on swine pericardium selected from animals which have an individual diet [48, 49].

Designing and creating a thin, self-positioning frame for the valve, presenting with high radial force and complete low-profile delivery system is another crucial step. Stent, constituting a scaffold will be laser cut from respective and properly treated cobalt-chromium alloy to enhance its durability and biocompatibility.

Positive completion of this phase and creation of functional prototype of TAVI system enables transition to the second stage of the project, covering the evaluation of feasibility, ease of implantation and safety in long-term observation on a large animal model. Findings of this phase will translate into diminishing the hazard for patients during enrollment for clinical trial and its results will be more unambiguous.

\section{Current state of the project (as of the mid 2017)}

To date, the project has already been in progress for more than 2.5 years. During this time important milestones have been accomplished. First of all, the scaffold of the valve was designed and created, as well as a prototype delivery system. Secondly, from among dozens of various polymers, the most optimal one was chosen and tested within the animal model within the aspect of biocompatibility. Recently, artificial and biological valve prototypes were constructed and tested with the use of flow pump [50]. The tests showed proper function of the opening/closing mechanism with preserved large area of opening. Concurrently, the InFlow-dedicated TAVI balloon was tested in in-vivo settings. Functionality was confirmed, with a new balloon pattern enabling precise positioning of implanted valve and reducing frequency of vascular complications connected with in-vessel maneuvering of the delivery system. The first implantations of both biological and polymeric valve prototypes with a dedicated delivery system have been performed during the first half of August 2017. Ovine was chosen as the most adequate animal model.

\section{Conclusions}

Cribier's first performed TAVI procedure marked the beginning of a revolution of severe AS treatment. Clinical trials and registries confirmed the efficacy and safety of the new method, simultaneously outlining the most frequent and severe complications, pointing out possible flaws and inadequacies. New designs and technologies, addressing the most critical issues, as well as continuous education and gathering of experience by physicians will hopefully contribute to reducing adverse event frequency and severity in the near future. Additionally, improving the method will translate into a possibility to implement it into lower risk groups and extending its range. Undertaking the challenge of developing new product by CardValve Consortium is a good sign that TAVI development market is not limited to a few main players. What is more, proposed solutions will result in creating a technologically advanced device, positively influencing patient comfort, safety and diminishing costs of the procedure, making it more within reach for patients. If the created product confirms its efficacy and ease of use, it can be successfully used as a basis for developing and implementing consecutive new technologies in the cardiovascular field. TAVI holds a great potential for improvement and becoming the gold standard in AS treatment, surpassing the classic methods. Only time will tell whether it meets expectations. 


\section{Acknowledgements}

CardValve Consortium (in alphabetical order): Bajdak Karolina, Broja Lucyna, Chodór Piotr, Cisowski Marek, Dobrzyński Piotr, Dominiak Aleksandra, Fernandez Carlos, Foltyn Tomasz, Frydrysiak Piotr, Gąsior Mariusz, Głowa Joanna, Gniłka Jacek, Guc Michał, Gwiazdowska-Nowotka Beata, Hawranek Michał, Hurkała Leszek, Jackiewicz Wanda, Janas Adam, Jelonek Katarzyna, Klein Wojciech, Krauze Agata, Małota Zbigniew, Niemiec-Cyganek Aleksandra, Płowiecki Emil, Sobczyk Jolanta, Sojka Elżbieta, Wasyluk Łukasz, Wilczek Krzysztof, Wilczek Piotr, Włodarczyk Jakub, Zembala Marian.

Funding: Planned complete cost of the project 14,8 mln PLN. Consortium CardValve under the leadership of American Heart of Poland SA has received funding of 11,6 mln PLN from National Centre for Research and Development under the frame of STRATEGMED project. The grant number: StrategMed 1/233166/6/NCBR/2014.

Conflict of interest: K. Milewski, P. Buszman, M. Michalak, W. Domaradzki, W. Gerber, J. Śliwka, J. Nożyński, M. Sobota, P. Hirnle, M. Białek-Brodocz, M. Zembala, M. Pawlak, E. Płowiecki, J. Kasperczyk, A Mężyk, P. Buszman: InFlow grant funding; M. Kachel, A. Bochenek: None declared.

\section{References}

1. Nkomo VT, Gardin TN, Skelton JS, et al. Burden of valvular heart diseases: a population-based study. Lancet. 2006; 368(9540): 1005-1011.

2. Vahanian A, Alfieri, O, Andreotti F, et al. ESC Committee for Practice Guidelines (CPG), Joint Task Force on the Management of Valvular Heart Disease of the European Society of Cardiology (ESC), European Association for Cardio-Thoracic Surgery (EACTS). Guidelines on the management of valvular heart disease (version 2012): the Joint Task Force on the Management of Valvular Heart Disease of the European Society of Cardiology (ESC) and the European Association for Cardio-Thoracic Surgery (EACTS). Eur J Cardiothorac Surg. 2012; 42(4): S1-44, doi: 10.1093/ejcts/ezs455, indexed in Pubmed: 22922698.

3. Dal-Bianco JP, Khandheria BK, Mookadam F, et al. Management of asymptomatic severe aortic stenosis. J Am Coll Cardiol. 2008; 52(16): 1279-1292, doi: 10.1016/j.jacc.2008.07.020, indexed in Pubmed: 18929238.

4. Iung B, Cachier A, Baron G, et al. Decision-making in elderly patients with severe aortic stenosis: why are so many denied surgery? Eur Heart J. 2005; 26(24): 2714-2720, doi: 10.1093/ eurheartj/ehi471, indexed in Pubmed: 16141261.

5. Cribier A. Development of transcatheter aortic valve implantation (TAVI): a 20-year odyssey. Arch Cardiovasc Dis. 2012; 105(3): 146-52, doi:10.1016/j.acvd.2012.01.005, indexed in Pubmed: 22520797.
6. Cribier A, Eltchaninoff H, Bash A, et al. Percutaneous transcatheter implantation of an aortic valve prosthesis for calcific aortic stenosis: first human case description. Circulation. 2002; 106(24): 3006-3008, indexed in Pubmed: 12473543.

7. Di Mario C, Eltchaninoff H, Moat N, et al. Transcatheter Valve Treatment Sentinel Registry (TCVT) Investigators of the EURObservational Research Programme (EORP) of the European Society of Cardiology. The 2011-12 pilot European Sentinel Registry of Transcatheter Aortic Valve Implantation: in-hospital results in 4,571 patients. EuroIntervention. 2013; 8(12): 1362-1371, doi: 10.4244/EIJV8I12A209, indexed in Pubmed: 23256965.

8. Kapadia SR, Leon MB, Makkar RR, et al. PARTNER trial investigators. 5-year outcomes of transcatheter aortic valve replacement compared with standard treatment for patients with inoperable aortic stenosis (PARTNER 1): a randomised controlled trial. Lancet. 2015; 385(9986): 2485-2491, doi:10.1016/S01406736(15)60290-2, indexed in Pubmed: 25788231.

9. Nielsen HH, Klaaborg KE, Nissen H, et al. A prospective, randomised trial of transapical transcatheter aortic valve implantation vs. surgical aortic valve replacement in operable elderly patients with aortic stenosis: the STACCATO trial. EuroIntervention. 2012; 8(3): 383-389, doi:10.4244/EIJV8I3A58, indexed in Pubmed: 22581299.

10. Siontis GCM, Praz F, Pilgrim T, et al. Transcatheter aortic valve implantation vs. surgical aortic valve replacement for treatment of severe aortic stenosis: a meta-analysis of randomized trials. Eur Heart J. 2016; 37(47): 3503-3512, doi: 10.1093/eurheartj/ ehw225, indexed in Pubmed: 27389906.

11. Mack MJ, Leon MB, Smith CR, et al. PARTNER 1 trial investigators. 5-year outcomes of transcatheter aortic valve replacement or surgical aortic valve replacement for high surgical risk patients with aortic stenosis (PARTNER 1): a randomised controlled trial. Lancet. 2015; 385(9986): 2477-2484, doi:10.1016/ S0140-6736(15)60308-7, indexed in Pubmed: 25788234.

12. Deeb GM, Reardon MJ, Chetcuti S, et al. CoreValve US Clinical Investigators. 3-Year Outcomes in High-Risk Patients Who Underwent Surgical or Transcatheter Aortic Valve Replacement. J Am Coll Cardiol. 2016; 67(22): 2565-2574, doi: 10.1016/j. jacc.2016.03.506, indexed in Pubmed: 27050187.

13. Søndergaard L, Steinbrüchel DA, Ihlemann N, et al. Two-Year Outcomes in Patients With Severe Aortic Valve Stenosis Randomized to Transcatheter Versus Surgical Aortic Valve Replacement: The All-Comers Nordic Aortic Valve Intervention Randomized Clinical Trial. Circ Cardiovasc Interv. 2016; 9(6): e003665, doi: 10.1161/CIRCINTERVENTIONS.115.003665, indexed in Pubmed: 27296202.

14. Sondergaard L. Clinical, safety and echocardiographic outcomes from the NOTION trial: 4 year follow-up data in all-comer patients with severe aortic valve stenosis, EuroPCR Annual Meeting 16-19 May, 2017.

15. Leon MB, Smith CR, Mack MJ, et al. for the PARTNER 2 Investigators. Transcatheter or surgical aortic-valve replacement in intermediate-risk patients. N Engl J Med. 2016; 374(17): 1609-1620, doi: 10.1056/NEJMoa1514616.

16. Reardon MJ, Van Mieghem NM, Popma JJ, et al. SURTAVI Investigators. Surgical or Transcatheter Aortic-Valve Replacement in Intermediate-Risk Patients. N Engl J Med. 2017; 376(14): 1321-1331, doi: 10.1056/NEJMoa1700456, indexed in Pubmed: 28304219.

17. Mylotte D, Osnabrugge R, Windecker S, et al. Transcatheter aortic valve replacement in Europe: adoption trends and factors influencing device utilization. J Am Coll Cardiol. 2013; 62(3): 210-219, doi: 10.1016/j.jacc.2013.03.074, indexed in Pubmed: 23684674. 
18. Fraccaro C, Napodano M, Tarantini G. Conduction disorders in the setting of transcatheter aortic valve implantation: a clinical perspective. Catheter Cardiovasc Interv. 2013; 81(7): 1217-1223, doi: 10.1002/ccd.24713, indexed in Pubmed: 23456893.

19. Mollmann H, Kim WK, Kempfert J, et al. Complications of transcatheter aortic valve implantation (TAVI): how to avoid and treat them. Heart. 2015; 101(11): 900-908, doi: 10.1136/ heartjnl-2013-304708, indexed in Pubmed: 25661821.

20. Ghanem A, Naderi AS, Frerker C, et al. Mechanisms and Prevention of TAVI-related cerebrovascular events. Curr Pharm Des. 2016; 22(13): 1879-1887, indexed in Pubmed: 26675314.

21. Bourantas CV, Serruys PW. Evolution of transcatheter aortic valve replacement. Circ Res. 2014; 114(6): 1037-1051, doi: 10.1161/CIRCRESAHA.114.302292, indexed in Pubmed: 24625728 .

22. Ribeiro HB, Urena M, Kuck KH, et al. Edwards CENTERA valve. EuroIntervention. 2012; 8(Suppl Q): Q79-82, doi: 10.4244/ EIJV8SQA14, indexed in Pubmed: 22995117.

23. Arsalan M, Walther T. Durability of prostheses for transcatheter aortic valve implantation. Nat Rev Cardiol. 2016; 13(6): 360-367, doi: 10.1038/nrcardio.2016.43, indexed in Pubmed: 27053461.

24. Kariori M, Kalogeras K, Vavuranakis M. The next era of transcatheter aortic valve implantation (TAVI): fully repositionable, resheathable and retrievable prostheses? Hosp Chron. 2014; 9(No 2).

25. Abramowitz Y, Chakravarty T, Jilaihawi H, et al. Update on New Devices for Transcatheter Aortic Valve Replacement. J Struct Heart Dis. 2015; 1(3): 112-126, doi: 10.12945/j.jshd.2015.019-14.

26. Jones BM, Krishnaswamy A. New TAVR Devices: European Experience and Status of US Trials. Cardiac Interventions Today. 2016; 10(2).

27. Kleiman NS, Reardon MJ. Advances in transcatheter aortic valve replacement. Methodist Debakey Cardiovasc J. 2016; 12(1): 33-36, doi: 10.14797/mdcj-12-1-33, indexed in Pubmed: 27127560.

28. Herrmann HC, Thourani VH, Kodali SK, et al. PARTNER Investigators. One-Year Clinical Outcomes With SAPIEN 3 Transcatheter Aortic Valve Replacement in High-Risk and Inoperable Patients With Severe Aortic Stenosis. Circulation. 2016; 134(2): 130-140, doi: 10.1161/CIRCULATIONAHA.116.022797, indexed in Pubmed: 27400898.

29. O'Riordan M. Boston Scientific Recalls All Lotus Valves, Including Lotus With Depth Guard. http://www.tctmd.com (2017).

30. Manoharan G. Clinical Outcomes at 1 Year with a Repositionable Self-Expanding Transcatheter Aortic Valve, Transcatheter Cardiovascular Therapeutics (TCT) Annual Meeting October 12, 2015.

31. Forrest JK. 30-Day Safety and Echocardiographic Outcomes Following Transcatheter Aortic Valve Replacement with the SelfExpanding Repositionable Evolut PRO System, American College of Cardiology (ACC) Annual Meeting March 17-19, 2017.

32. ACC 2017: FDA approves launch of CoreValve Evolut Pro, https://cardiovascularnews.com; March 212017.

33. Meredith IT, Hood KL, Haratani N, et al. Boston Scientific Lotus valve. EuroIntervention. 2012; 8(Suppl Q): Q70-Q74, doi: 10.4244/EIJV8SQA12, indexed in Pubmed: 22995115.

34. Meredith IT, Walters DL, Dumonteil N, et al. 1-Year Outcomes With the Fully Repositionable and Retrievable Lotus Transcatheter Aortic Replacement Valve in 120 High-Risk Surgical Patients With Severe Aortic Stenosis: Results of the REPRISE II Study.
JACC Cardiovasc Interv. 2016; 9(4): 376-384, doi: 10.1016/j. jcin.2015.10.024, indexed in Pubmed: 26892084.

35. Meredith IT. First Report of Discharge/7-day Results from the Lotus Edge Feasibility Trial,_Transcatheter Cardiovascular Therapeutics (TCT) Annual Meeting October 30, 2016.

36. Treede H, Rastan A, Ferrari M, et al. JenaValve. EuroIntervention. 2012; 8(Suppl Q): Q88-Q93, doi: 10.4244/EIJV8SQA16, indexed in Pubmed:22995119.

37. Manoharan G, Spence MS, Rodes-Cabau J, et al. St Jude Medical Portico valve. EuroIntervention. 2012; 8(Suppl Q): Q97-Q101, doi:10.4244/EIJV8SQA18, indexed in Pubmed: 22995122.

38. Perlman G, Cheung A, Dumont E, et al. Transcatheter aortic valve replacement with the Portico valve: one-year results of the early Canadian experience. EuroIntervention. 2017; 12(13): 1653-1659, doi: 10.4244/eij-d-16-00299, indexed in Pubmed: 28105999.

39. Bijuklic K, Tubler T, Low RI, et al. Direct Flow Medical valve. EuroIntervention. 2012; 8(Suppl Q): Q75-Q78.

40. Latib A, Maisano F, Colombo A, et al. Transcatheter aortic valve implantation of the direct flow medical aortic valve with minimal or no contrast. Cardiovasc Revasc Med. 2014; 15(4): 252-257, doi: 10.1016/j.carrev.2014.03.003, indexed in Pubmed: 24721585.

41. TAVI company Direct Flow Medical closes after failing to secure funding, https://cardiovascularnews.com; January 16, 2017.

42. Tchetche D. 30-day Outcomes of the CENTERA Trial - a New Self-Expanding Transcatheter Heart Valve, EuroPCR Annual Meeting 16-19 May, 2017.

43. Bagur R, Teefy PJ, Kiaii B, et al. First North American experience with the transfemoral ACURATE-neoTM self-expanding transcatheter aortic bioprosthesis. Catheter Cardiovasc Interv. 2017; 90(1): 130-138, doi: 10.1002/ccd.26802, indexed in Pubmed: 27677241.

44. Mollmann H, Walther T, Siqueira D, et al. Transfemoral TAVI using the self-expanding ACURATE neo prosthesis: one-year outcomes of the multicentre. EuroIntervention. 2017; 13(9): e1040-e1046, doi: 10.4244/EIJ-D-17-00187, indexed in Pubmed: 28804056.

45. Sundermann SH, Grunenfelder J, Corti R, et al. Feasibility of the Engager ${ }^{\mathrm{TM}}$ aortic transcatheter valve system using a flexible over-the-wire design. Eur J Cardiothorac Surg. 2012; 42(4): e48-e52, doi: 10.1093/ejcts/ezs389, indexed in Pubmed: 22743081.

46. Sundermann SH, Holzhey D, Bleiziffer S, et al. Second-generation transapical valves: the Medtronic Engager system. Multimed Man Cardiothorac Surg. 2014; 2014: mmu001, doi: 10.1093/mmcts/mmu001, indexed in Pubmed: 24568935.

47. Medtronic 23mm EngagerTM Transcatheter Aortic Bioprosthesis. Model: ME-TA2-B23. Patient Management Recommendations and Recall, http://www.moph.gov.lb (2015).

48. Mężyk A, Jureczko P, Machoczek T, Konopelska A, Pawlak M. Tensile tests of porcine pericardial tissue for aortic heart valve leaflets. CRC Press/Balkema, Cape Town 2016: 618-623.

49. Mezyk A, Klein W, Pawlak M, et al. Preliminary tests of new composite material based on shape memory alloys for artificial aortic valve leaflets. IEEE. 2016: 1-3, doi: 10.1109/biosmart.2016.7835468.

50. Pawlak M, Klein W, Gniłka J, et al. Numerical modeling of leaflets for artificial aortic valves with SPH method. CMBE. 2017: 1288-1291. 